\title{
Pengembangan Program Studi Manajemen Zakat dan Wakaf Fakultas Syariah IAIN Surakarta Berbasis Kebutuhan Masyarakat
}

\author{
Ah. Kholis Hayatuddin \\ Institut Agama Islam Negeri (IAIN) Surakarta \\ Email. kholis.hayatuddin@yahoo.com
}

\begin{abstract}
The Importance of Existence from Mazawa Study Program must also be balanced with the development of study programs that meet the needs of the community, namely to produce the energy needed by the community. Therefore the development of Mazawa's products that are attractive to people's needs is very important, with the hope that quality can compete at regional, national and even international levels. The development of advanced communities with complex problems is a challenge for the development of Zakat Management and Waqf needed to predict future community needs.

Keywords : $\quad$ Development Of Study Program, Based On Community Needs
\end{abstract}

\section{Latar Belakang}

Visi pendidikan nasional adalah terwujudnya sistem pendidikan sebagai pranata sosial yang kuat dan berwibawa untuk memberdayakan semua warga negara Indonesia agar berkembang menjadi manusia yang berkualitas sehingga mampu dan proaktif menjawab tantangan zaman yang selalu berubah. Sedangkan misi pendidikan nasional antara lain meningkatkan mutu pendidikan sehingga memiliki daya saing di tingkat nasional, regional dan internasional. (Depdiknas, 2008: 2).

Untuk mewujudkan visi dan menjalankan misi pendidikan nasional tersebut, pemerintah berupaya untuk menyelenggarakan pendidikan yang bermutu sebagaimana yang diamanatkan dalam Undang-Undang Nomor 20 Tahun 2003 tentang Sistem Pendidikan Nasional pada Pasal 50 Ayat (3).

Pendidikan masa depan menuntut lembaga-lembaga pendidikan membuat rancangan program yang dapat mengantisipasi kebutuahn masyarakat terutama jenis-jenis pekerjaan yang relevan dengan lulusan prodi/jurusan di berbagai lembaga pendidikan tinggi. Pengembangan dapat dilakukan melalui pengembangan prodi agar mampu menjawab tantangan global melalui peningkatan kualitas lulusan, manajemen kelembagaan, dan peningkatan kompetensi dosen baik kualitas maupun kualifikasinya melalui berbagai pendekatan.

Masalah pengembangan aktivitas kependidikan Islam di Indonesia pada dasarnya sudah berlangsung sejak sebelum Indonesia merdeka hingga sekarang dan hingga yang akan datang. Dalam realitas sejarahnya, sejak awal kemer dekaannya bangsa Indonesia telah memberikan perhatian dan pengakuan yang relatif tinggi terhadap sumbangan besar pendidikan Islam dalam upaya mendidik dan mencerdaskan kehidupan bangsa. Hal ini di samping merupakan prestasi tersendiri yang telah diraih umat Islam, juga sekaligus merupakan tantangan yang memerlukan respon positif dari para pemikir dan pengelola pendidikan Islam di Indonesia. (Muhaimin, 2003: 23). 
Program Studi Manajemen Zakat dan Waqaf Fakultas Syariah IAIN Surakarta yang dibuka pada tahun 2016 mempunyai arti penting, karena posisinya sebagai berikut:

1. Di Surakarta telah tumbuh subur Lembaga lembaga Amil zakat dari berbagai ormas keagamaan, dan Baznas milik pemerintah serta tumbuh suburnya komunitas komunitas yang memiliki kepedulian sosial yang tinggi, yang masih banyak membutuhkan Sumber Daya Manusia yang amanah, professional dan terampil. Prodi Mazawa siap mencetak SDM yang dibutuhkan tersebut.

2. Adanya pandangan dalam masyarakat beragama yang memisahkan antara urusan akherat dan urusan dunia, sehingga banyak terjadi ketimpangan, satu sisi ada yang mengalami kemajuan spiritualnya tapi kehidupan dunianya tertinggal. Sementara sisi yang lain, kehidupan dunianya mengalami kemajuan, akan tetapi terlepas dari nilainilai keislaman , sehingga Prodi Manajemen Zakat dan Wakaf dan Fakultas Syariah diharapkan mampu memberi pengetahuan dan pemahaman yang utuh, bahwa agama dan dunia merupakan dua hal yang saling memperkuat dalam mencapai kebahagiaan hidup dunia dan akherat.

3. Pada sektor formal, di Surakarta dan sekitarnya terdapat cukup banyak pondok pesantren (2.510), Madrasah Aliyah (MA) dan SMU/SMK, sehingga memberi peluang kepada Prodi Manajemen Zakat dan Wakaf untuk menampung para santri dan para siswanya meneruskan jenjang pendidikan yang lebih tinggi.

Peluang-peluang di atas yang menegaskan pentingnya eksistensi keberadaan Prodi Mazawa juga harus diimbangi dengan pengembangan prodi yang menyentuh pada kebutuhan masyarakat, yakni menghasilkan tenaga yang dibutuhkan oleh masyarakat. Karenanya pengembangan Prodi Mazawa yang mengacu pada kebutuhan masyarakat menjadi amat penting, dengan harapan kualitas lulusan dapat bersaing pada tingkat regional, nasional bahkan internasional. Perkembangan masyarakat yang semakin maju dengan problema yang kompleks menjadi tantangan bagi lulusan Manajemen Zakat dan Waqaf yang seharusnya dapat memprediksi kebutuhan masyarakat ke depan.

Oleh karena itu pengembangan Prodi Mazawa ke depan harus menghasilkan sarjana dengan kompetensi manajemen, yang dapat mengelola program-program untuk memfasilitasi pengembangan zakat dan waqaf. Prodi Mazawa juga harus memahami idealisme, budaya dan karakteristik pendidikan Islam, yang tidak bisa lepas dari kehidupan umat Islam Indonesia. Mazawa harus mampu melahirkan sarjana yang paham dan terampil bekerja dalam birokrasi. Dengan demikian budaya dan etika birokrasi harus dibahas, dilatih dan diuji kompetensinya. Di samping itu, Mazawa harus mampu melahirkan sarjana yang paham entrepreneurship, terampil mengelola dan mengembangkan organisasi pendidikan yang mampu bersaing dengan institusi lain.

Di sinilah letak signifikansi dari tema penelitian yang penulis angkat, kontribusinya terasa amat penting, khususnya dalam diskursus pengembangan Program Studi oleh lembaga-lembaga terkait. Dalam penelitian ini penulis mencoba mengkaji lebih lanjut “ Pengembangan Program Studi Manajemen Zakat Dan Wakaf Fakultas Syariah Iain Surakarta Berbasis Kebutuhan Masyarakat”.

\section{Teori dan Metode}

\subsection{Kajian Teori}

\subsubsection{Manajemen Pendidikan (Pengembangan Program Studi)}

Manajemen berasal dari kata manage (to manage) yang berarti "to conduct or to carry on, to direct" yang diartikan dengan "mengurus, mengatur, melaksanakan, mengelola. Adapun dari segi Istilah banyak para ahli telah memberikan pengertian manajemen, dengan formulasi yang berbeda-beda. Salah satunya menurut Sondang 
bahwa manajemen dapat didefinisikan sebagai 'kemampuan atau ketrampilan untuk memperoleh sesuatu hasil dalam rangka pencapaian tujuan melalui kegiatan-kegiatan orang lain'. Dengan demikian dapat pula dikatakan bahwa manajemen merupakan alat pelaksana utama administrasi. (Sondang P. Siagian, 1997: 5)

Secara etimologis, kata manajemen merupakan terjemahan dari management (bahasa Inggris). Kata management tersebut berasal dari kata manage atau magiare yang berarti melatih kuda dalam melangkahkan kakinya. Dalam pengertian manajemen tersebut terkandung dalam dua kegiatan, yaitu kegiatan berpikir (mind) dan kegiatan tingkah laku (action). (Eka Prihatin, 2011: 1). Analisis etimologis kata manajemen di atas sama dengan yang dikemukakan oleh Hasan Shadily dalam Kamus Inggris Indonesia yaitu: ... dari kata kerja to manage yang artinya mengurus, mengatur, menggerakkan dan mengelola. (Jhon M. Echol, 1996: 3722). Dengan demikian manajemen secara bahasa adalah pengurusan, pengaturan, penggerakan dan pengelolaan.

Suharsimi Arikunto dan Lia Yuliana mengemukakan bahwa manajemen berasal dari bahasa Inggris, yaitu administration sebagai the management of executive affairs. Dengan pengertian tersebut maka manajemen diartikan bukan hanya sekedar kegiatan tulis menulis, melainkan pula pengeturan dalam arti luas. (Suharsimi Arikunto, 2012: 2)

Secara terminology manajemen sering disandingkan dengan administrasi, sehingga muncul tiga pandangan yang berbeda: 1) memandang administrasi lebih luas dari pada manajemen; 2) mengartikan manajemen lebih luas dari pada administrasi; 3) menganggap manajemen sama dengan administrasi. (E. Mulyasa, 2003: 193)

John D. Millet membatasi manajemen is the process of directing and facilitating the work of people organized in formal groups to achieve a desired goal (adalah suatu proses pengarahan dan pemberian fasilitas kerja kepada orang yang diorganisasikan dalam kelompok formal dan untuk pencapaian tujuan). (Siswanto, 2010: 1)

Millet lebih menekankan bahwa manajemen sebagai suatu proses, yaitu suatu rangkaian aktivitas yang satu sama lain saling berurutan.

a. Proses pengarahan (process of directing), yaitu suatu rangkaian kegiatan untuk memberikan petunjuk atau instruksi dari seorang atasan kepada bawahan atau kepada orang yang diorganisasikan dalam kelompok formal dan untuk pencapaian tujuan.

b. Proses pemberian fasilitas kerja (process of facilitating the work), yaitu rangkaian kegiatan untuk memberikan sarana dan prasarana serta jasa yang memudahkan pelaksanaan pekerjaan dari seorang atasan kepada bawahan atau kepada orang yang diorganisasikan dalam kelompok formal dan untuk pencapaian tujuan. (Siswanto, 2010: 1)

Lembaga-lembaga yang mempunyai konsentrasi di bidang pendidikan. Memiliki fungsi ganda. Fungsi pertama, lembaga tersebut berkewajiban menyampaikan nilainilai Islam kepada para mahasiswa, sehingga dapat melahirkan para sarjana yang memiliki pengetahuan Islam secara luas, memiliki tanggung jawa tehadap kewajiban Islam, berakhlaqul karimah, selalu bisa menjadi suri tauladan bagi masyarakat dimana mereka berada. Fungsi kedua, lembaga tersebut berkewajiban melahirkan sarjana yang meliki konsep yang jelas tentang pendidikan Islam yang selalu mengacu dari perspektif qur'ani dan hadisi serta pendapat ulama Islam yang telah memiliki konsep pendidikan Islam sebagai ilmu. Dalam tulisan ini penulis bermaksud memaparkan secara sederhana mengenai hakikat pendidiakan Islam dantujuannya, serta pendapatpendapat ulama tentang hal tersebut. 


\subsection{Metode Penelitian}

Metode yang digunakan dalam penelitian ini metode analisis- deskriptif (analytical-descriftif method), untuk menggambarkan suatu gejala, peristiwa atau kejadian yang faktual dan aktual sebagaiman adanya pada saat penelitian dilakukan, lalu kemudian melakukan analisis data dengan cara mengorganisir data berupa berupa laporan, biografi, artikel, atau buku-buku pedoman dan sebagainya. Sehingga diharapkan akan memperoleh pemahaman dan penafsiran secara mendalam mengenai makna dari kenyataan yang ditemukan dilapangan. (Lexi J. Moloeng, 2004: 194)

Adapun langkah-langkah penelitian ini adalah sebagai berikut: Pertama penulis akan menginventarisasi data dan menyeleksinya, khususnya acuan tertulis pengembangan Program Studi Manajemen Zakat dan Wakaf di Fakultas Syariah IAIN Surakarta, semua yang berkaitan dengan prosedural kebijakan dan pengembangan Prodi Mazawa tersebut akan dikumpulkan terlebih dahulu. Kedua, penulis dengan cermat akan mengkaji data tersebut secara komprehensif dan kemudian mengabstraksikan melalui metode deskriptif.

\section{Hasil dan Pembahasan}

\subsection{Hasil analisis data}

Uji hipotesis digunakan untuk menguji hipotesis penelitian yang telah dirumuskan sebelumnya, yaitu untuk mengetahui pengaruh variabel Capital Adequacy Ratio (CAR), Non Performing Financing (NPF), Return on Asset (ROA), Biaya Operasional terhadap Pendaptan Operasional (BOPO), dan Financing to Deposit Ratio (FDR) terhadap Volume Pembiayaan Bank Umum Syariah.

Untuk prosedur analisis dalam pengembangan program studi MAZAWA berbasis kebutuhan masyarakat ini, penulis menggunakan analisis SWOT. Analisis SWOT merupakan salah satu metode analisis situasional yang menitikberatkan pada identifikasi beberapa faktor secara sistematis untuk merumuskan strategi perusahaan, organisasi, atau lembaga. SWOT sendiri merupakan akronim dari Strengths (kekuatan), Weaknesses (kelemahan), Opportunities (peluang), dan Threats (ancaman). (Freddy, 2004:18). Berikut ini adalah identifikasi SWOT dalam beberapa komponen dalam Prodi MAZAWA:

\section{a. Identifikasi SWOT Kurikulum Prodi MAZAWA}

Berdasarkan struktur kurikulum Prodi MAZAWA, perlu dilakukan review kurikulum yang melibatkan stakeholders yang terkait seperti dari BAZNAS, LAZIZ, dan juga mahasiswa. Oleh karena itu, peneliti melakukan wawancara dengan stakeholders sehingga Prodi MAZAWA akan mendapatkan masukan terkait kurikulum yang sesuai dengan kebutuhan masyarakat terkini. Adapun hasil wawancara dengan stakeholder terkait dengan kurikulum prodi MAZAWA adalah sebagai berikut:

\begin{tabular}{|l|l|}
\hline \multicolumn{1}{|c|}{ STAKEHOLDER } & TUNTUTAN DAN KEBUTUHAN \\
\hline $\begin{array}{l}\text { BAZNAS Karanganyar } \\
\text { (Drs. H. Sugiyarso H.S, S.Pd, }\end{array}$ & $\begin{array}{l}\text { Kurikulum Prodi MAZAWA harus } \\
\text { melakukan pengayaan terhadap }\end{array}$ \\
$\begin{array}{l}\text { S.H, M.Ag, M.Kn selaku Ketua } \\
\text { BAZNAS Karanganyar periode }\end{array}$ & $\begin{array}{l}\text { kurikulum sebelumnya dan } \\
\text { menambahkan mata kuliah IT } \\
\text { tahun 2016-2021) }\end{array}$ \\
sebagai mata kuliah baru di Prodi \\
\hline
\end{tabular}




\begin{tabular}{|l|l|}
\hline & $\begin{array}{l}\text { MAZAWA. Tujuannya agar lulusan } \\
\text { mampu mengoperasikan sistem } \\
\text { informasi, baik yang berkaitan } \\
\text { dengan SIM (Sistem Informasi } \\
\text { Manajemen) maupun SIA (Sistem }\end{array}$ \\
Informasi Akutansi) dan \\
menyesuaikan dengan \\
perkembangan zaman khususnya \\
program penghimpunan/fundrising.
\end{tabular}

Berdasarkan kurikulum Prodi MAZAWA dan masukan-masukan dari stakeholder di atas, maka berikut ini memuat kekuatan (strengths, S), kelemahan (weaknesses, W), peluang (opportunities, O), dan ancaman (threats, T), yang teridentifikasi:

\begin{tabular}{|c|c|}
\hline Strengths (kekuatan) & $\begin{array}{l}\text { Weaknesses } \\
\text { (kelemahan) }\end{array}$ \\
\hline $\begin{array}{l}\text { Integrasi kurikulum dengan mata } \\
\text { kuliah yang diajarkan. } \\
\text { Keterbukaan diri pimpinan Prodi } \\
\text { MAZAWA dan stakeholders lain } \\
\text { di IAIN Surakarta terhadap } \\
\text { perubahan }\end{array}$ & $\begin{array}{l}\text { Adaptasi mahasiswa yang cukup } \\
\text { lama terhadap mata kuliah yang } \\
\text { baru, karena belum pernah } \\
\text { diajarkan kepada kakak tingkat } \\
\text { mereka. } \\
\text { Kurangnya sarana pendukung }\end{array}$ \\
\hline
\end{tabular}


bermaksud menyesuaikan diri dengan kebutuhan pengguna lulusan dan masyarakat.

- Kekuatan proses pengajaran mata kuliah terletak pada kompetensi dosen yang mumpuni yang mana memungkinkan mahasiswa maksimal dalam proses pembelajaran.

- Mata kuliah pilihan mendorong kreativitas mahasiswa, baik dalam memilih dan mengalami proses pembelajarannya.

Opportunities (peluang)

- Kurikulum Prodi MAZAWA harus melakukan pengayaan terhadap kurikulum sebelumnya dan menambahkan mata kuliah IT sebagai mata kuliah baru di Prodi MAZAWA. Tujuannya agar lulusan mampu mengoperasikan sistem informasi, baik yang berkaitan dengan SIM (Sistem Informasi Manajemen) maupun SIA (Sistem Informasi Akutansi) dan menyesuaikan dengan perkembangan zaman khususnya program

penghimpunan/fundrising.

\section{(BAZNAS Karanganyar)}

- Kurikulum Prodi MAZAWA memberikan pendalaman pada mata kuliah yang terkait dengan keuangan syariah dan pengenalan SIMBA (Sistem Informasi Manajemen BAZNAS). (BAZNAS Sragen)

- Kita membutuhkan SDM Output lulusan manajemen zakat dan wakaf yang paham tentang fiqih zakat dan wakaf, faham manajemen, faham akutansi dan faham tentang system informasi dan teknologinya. Selain itu juga harus menguasai strategi fundrising dan pengelolaan SDM yang baik. Untuk menjadi amil yang profesional, lanjutnya, yang relevan dengan suatu mata kuliah. Bisa disiasati dengan sarana lain yang sepadan, namun sulit menjadi maksimal bagi proses pembelajaran.

Kurikulum Prodi MAZAWA disebut tidak 'idealis' karena mengacu pada kebutuhan pasar. Ini menjadi tantangan sekaligus peluang.
Adaptasi yang terus menerus perlu dan wajib dilakukan bagi dosen dan mahasiswa terhadap mata kuliah baru yang asing, mengingat 'kebutuhan pasar' adalah kata kunci di balik penyusunan kurikulum Prodi MAZAWA.

Ketidakcermatan dalam menentukan mata kuliah yang diganti dan yang menggantikan akan berimplikasi pada keseluruhan proses pengembangan Prodi MAZAWA di balik proses pembelajaran. 


\section{dibutuhkan basic training standar \\ amil. (LAZNAS AL-AZHAR)}

\section{b. Identifikasi SWOT Sumber Daya Manusia (SDM) Prodi MAZAWA}

Berdasarkan data dosen Prodi MAZAWA, perlu dilakukan review yang melibatkan stakeholders yang terkait seperti dari BAZNAS, LAZIZ, dan juga mahasiswa. Oleh karena itu, peneliti melakukan wawancara dengan stakeholders sehingga Prodi MAZAWA akan mendapatkan masukan terkait dosen yang sesuai dengan kebutuhan masyarakat terkini. Adapun hasil wawancara dengan stakeholder terkait adalah sebagai berikut:

\begin{tabular}{|l|l|}
\hline \multicolumn{1}{|c|}{ STAKEHOLDER } & \multicolumn{1}{|c|}{ TUNTUTAN DAN } \\
KEBUTUHAN
\end{tabular}

Berdasarkan Sumber Daya Manusia (SDM) Prodi MAZAWA dan masukanmasukan dari stakeholder di atas, maka berikut ini memuat kekuatan (strengths, S), kelemahan (weaknesses, W), peluang (opportunities, O), dan ancaman (threats, T), yang teridentifikasi:

\begin{tabular}{|l|ll|}
\hline \multicolumn{2}{|c|}{ Strengths (kekuatan) } & \multicolumn{2}{c|}{ Weaknesses } \\
(kelemahan)
\end{tabular}




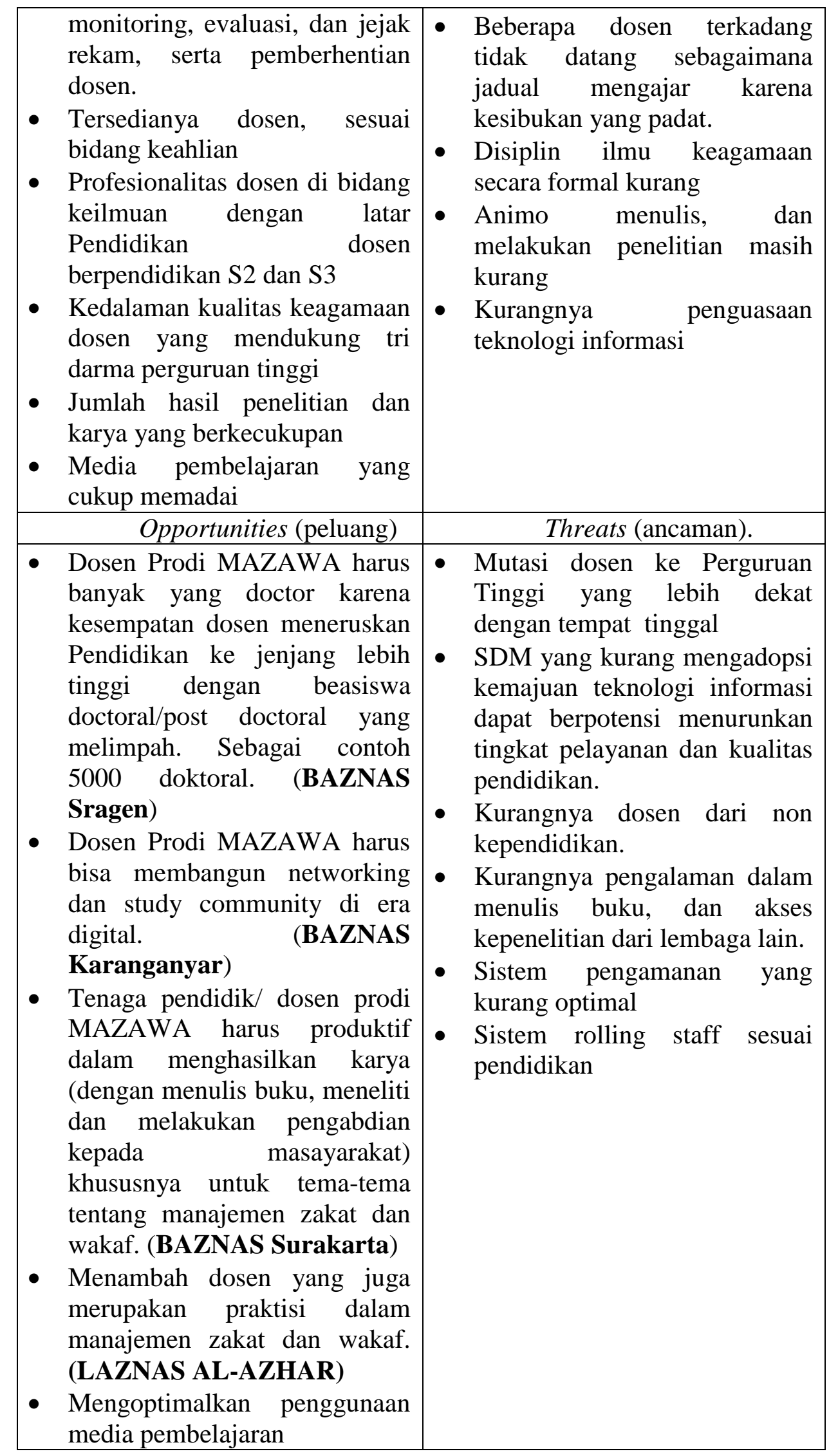

\section{c. Identifikasi SWOT Tata Kelola Prodi MAZAWA}

Berdasarkan tata kelola Prodi MAZAWA, perlu dilakukan evaluasi yang melibatkan stakeholders yang terkait seperti dari BAZNAS, LAZIZ, dan juga 
mahasiswa. Oleh karena itu, peneliti melakukan wawancara dengan stakeholders sehingga Prodi MAZAWA akan mendapatkan masukan terkait tata kelola yang sesuai dengan kebutuhan masyarakat terkini. Adapun hasil wawancara dengan stakeholder terkait adalah sebagai berikut:

\begin{tabular}{|c|c|}
\hline STAKEHOLDER & $\begin{array}{l}\text { TUNTUTAN } \\
\text { KEBUTUHAN }\end{array}$ \\
\hline $\begin{array}{l}\text { BAZNAS Karanganyar } \\
\text { (Drs. H. Sugiyarso H.S, S.Pd, } \\
\text { S.H, M.Ag, M.Kn selaku Ketua } \\
\text { BAZNAS Karanganyar periode } \\
\text { tahun 2016-2021) }\end{array}$ & $\begin{array}{l}\text { Prodi Manajemen Zakat dan Wakaf } \\
\text { adalah Prodi baru, sehingga dalam } \\
\text { pengelolaan diperlukan kerjasama } \\
\text { dengan berbagai pihak dalam } \\
\text { pengembangan program studi. Dari } \\
\text { kerjasama tersebut terbangun dialog } \\
\text { yang intensif dengan para praktisi } \\
\text { lembaga zakat wakaf. Melalui dialog } \\
\text { demikian, diharapkan kesenjangan } \\
\text { antara teori dan kebutuhan praktis } \\
\text { pengelolaan zakat wakaf dapat } \\
\text { dihindari. }\end{array}$ \\
\hline 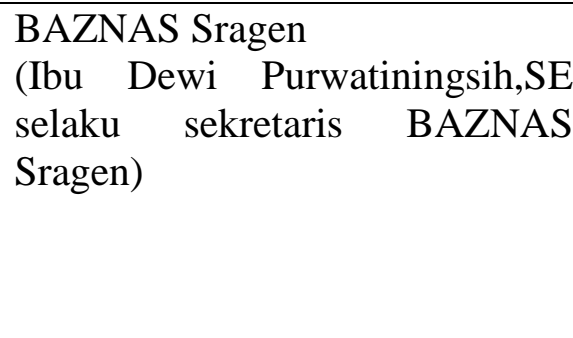 & $\begin{array}{l}\text { Perlu mengembangkan kerjasama } \\
\text { dengan BAZNAS atau LAZIS di eks } \\
\text { Karesidenan Surakarta dan } \\
\text { sekitarnya yang dapat dijadikan } \\
\text { mitra untuk mengembangkan } \\
\text { program yang dibutuhkan oleh } \\
\text { pengguna lulusan. }\end{array}$ \\
\hline $\begin{array}{l}\text { BAZNAS Surakarta } \\
\text { (Endang Suryana, SH.I selaku } \\
\text { Wakil Ketua III BAZNAS } \\
\text { Surakarta) }\end{array}$ & $\begin{array}{l}\text { Perlu adanya study banding terhadap } \\
\text { pengelolaan prodi MAZAWA di } \\
\text { beberapa Perguruan Tinggi yang } \\
\text { lain. }\end{array}$ \\
\hline 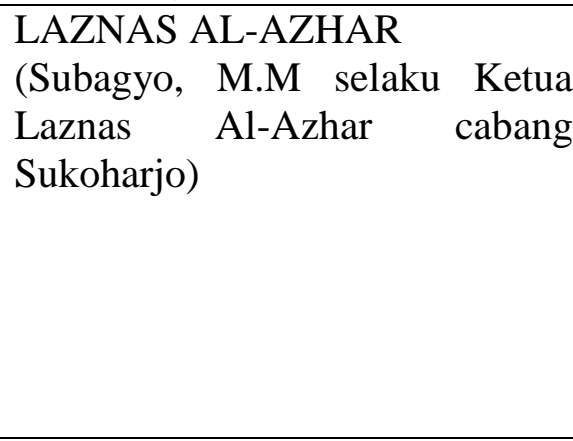 & $\begin{array}{l}\text { Perlu memperkuat legalitas } \\
\text { laboratorium ZISWAF Fasya } \\
\text { sehingga bisa digunakan oleh } \\
\text { mahasiswa untuk praktik langsung } \\
\text { dalam pengelolaan ZISWAF. Kami } \\
\text { juga akan menjalin kerjasama } \\
\text { dengan laboratorium ziswaf Fasya } \\
\text { sebagai Mitra Pengumpul Zakat } \\
\text { (MPZ) Laznas Al-Azhar. }\end{array}$ \\
\hline $\begin{array}{l}\text { Mahasiswa } \\
\text { (Ammar) }\end{array}$ & $\begin{array}{l}\text { Dalam pengelolaan prodi } \\
\text { MAZAWA, kami berharap prodi } \\
\text { MAZAWA bisa lebih meningkatkan } \\
\text { kualitas pelayanan akademik dan } \\
\text { non akademik sehingga memberikan } \\
\text { kenyaman kepada kami. }\end{array}$ \\
\hline
\end{tabular}

Berdasarkan Tata Kelola Prodi MAZAWA dan masukan-masukan dari stakeholder di atas, maka berikut ini memuat kekuatan (strengths, S), kelemahan (weaknesses, W), peluang (opportunities, O), dan ancaman (threats, T), yang teridentifikasi: 


\begin{tabular}{|c|c|}
\hline Strengths (kekuatan) & $\begin{array}{l}\text { Weaknesses } \\
\text { (kelemahan) }\end{array}$ \\
\hline $\begin{array}{l}\text { - Komitmen yang kuat dari } \\
\text { IAIN Surakarta dan Fakultas } \\
\text { Syariah untuk mengembangkan } \\
\text { Program Studi Manajemen Zakat } \\
\text { dan Wakaf, termasuk dalam } \\
\text { pengelolaan program pendidikan. } \\
\text { - Otonomi pengelolaan oleh } \\
\text { program studi masing-masing. } \\
\text { - Dukungan dari individu dan } \\
\text { kelembagaan yang berada di } \\
\text { lingkungan program studi sangat } \\
\text { membantu pimpinan progam } \\
\text { studi dalam pengelolaan program } \\
\text { studi } \\
\text { - Transparansi } \\
\text { pengelolaan program studi . }\end{array}$ & $\begin{array}{l}\text { - Kerjasama dan kemitraan } \\
\text { dengan pihak lain masih kurang } \\
\text { maksimal khususnya dalam } \\
\text { menyerap input. } \\
\text { - Pelayanan akademik dan } \\
\text { non akademik yang kurang } \\
\text { maksimal kepada mahasiswa. }\end{array}$ \\
\hline Opportunities (peluang) & Threats (ancaman). \\
\hline $\begin{array}{l}\text { - Prodi Manajemen Zakat dan } \\
\text { Wakaf adalah Prodi baru, } \\
\text { sehingga dalam pengelolaan } \\
\text { diperlukan kerjasama dengan } \\
\text { berbagai pihak dalam } \\
\text { pengembangan program studi. } \\
\text { Dari kerjasama tersebut } \\
\text { terbangun dialog yang intensif } \\
\text { dengan para praktisi lembaga } \\
\text { zakat wakaf. Melalui dialog } \\
\text { demikian, diharapkan } \\
\text { kesenjangan antara teori dan } \\
\text { kebutuhan praktis pengelolaan } \\
\text { zakat wakaf dapat dihindari. } \\
\text { (BAZNAS Karanganyar) } \\
\text { - Perlu mengembangkan } \\
\text { kerjasama dengan BAZNAS atau } \\
\text { LAZIS di eks Karesidenan } \\
\text { Surakarta dan sekitarnya yang } \\
\text { dapat dijadikan mitra untuk } \\
\text { mengembangkan program yang } \\
\text { dibutuhkan oleh pengguna } \\
\text { lulusan. (BAZNAS Sragen) } \\
\text { - Perlu memperkuat legalitas } \\
\text { laboratorium ZISWAF Fasya } \\
\text { sehingga bisa digunakan oleh } \\
\text { mahasiswa untuk praktik } \\
\text { langsung dalam pengelolaan } \\
\text { ZISWAF. Kami juga akan } \\
\text { menjalin kerjasama dengan } \\
\text { laboratorium ziswaf Fasya }\end{array}$ & $\begin{array}{l}\text { - } \text { Banyak perguruan tinggi } \\
\text { yang sudah mengadakan } \\
\text { kerjasama dengan pihak } \\
\text { pengguna lulusan baik } \\
\text { pemerintah maupun swasta. }\end{array}$ \\
\hline
\end{tabular}




\begin{tabular}{|l|l|l|}
\hline sebagai Mitra Pengumpul Zakat & \\
(MPZ) Laznas Al-Azhar. & \\
(LAZNAS AL-AZHAR) & \\
- Perlu adanya study banding & \\
terhadap pengelolaan prodi & \\
MAZAWA di beberapa & \\
Perguruan Tinggi yang lain. & \\
(BAZNAS Surakarta) &
\end{tabular}

\section{d. Identifikasi SWOT Sarana dan Prasarana Prodi MAZAWA}

Prodi MAZAWA tetap terbuka dengan masukan-masukan stakeholders terkait sarana dan prasarana yang telah dimiliki. Adapun tuntutan dan kebutuhan dari stakeholder terkait dengan sarana dan prasarana prodi MAZAWA adalah sebagai berikut:

\begin{tabular}{|c|c|}
\hline STAKEHOLDER & $\begin{array}{l}\text { TUNTUTAN } \\
\text { KEBUTUHAN }\end{array}$ \\
\hline $\begin{array}{l}\text { BAZNAS Karanganyar } \\
\text { (Drs. H. Sugiyarso H.S, S.Pd, } \\
\text { S.H, M.Ag, M.Kn selaku Ketua } \\
\text { BAZNAS Karanganyar periode } \\
\text { tahun 2016-2021) }\end{array}$ & $\begin{array}{l}\text { Perlu ditingkatkan pemanfaatan } \\
\text { sarana dan prasarana yang sudah } \\
\text { ada di Prodi MAZAWA. }\end{array}$ \\
\hline \begin{tabular}{l}
\multicolumn{3}{l}{ BAZNAS Sragen } \\
(Ibu Dewi Purwatiningsih,SE \\
selaku $\quad$ sekretaris BAZNAS \\
Sragen)
\end{tabular} & $\begin{array}{l}\text { Perkembangan teknologi informasi } \\
\text { yang sangat cepat berdampak pada } \\
\text { keharusan melakukan updating } \\
\text { sistem informasi secara } \\
\text { berkelanjutan. Hal ini penting } \\
\text { karena untuk Prodi MAZAWA } \\
\text { dibutuhkan pengembangan SIM dan } \\
\text { SIA dalam pengenalan pengelolaan } \\
\text { ZISWAF untuk mahasiswa. }\end{array}$ \\
\hline $\begin{array}{l}\text { LAZNAS AL-AZHAR } \\
\text { (Subagyo, M.M selaku Ketua } \\
\text { Laznas Al-Azhar cabang } \\
\text { Sukoharjo) }\end{array}$ & $\begin{array}{l}\text { Perlu penguatan dan pengembangan } \\
\text { Laboratorium ZISWAF Mazawa. }\end{array}$ \\
\hline Mahasiswa (Ammar) & $\begin{array}{l}\text { Perlu ditambah buku-buku referensi } \\
\text { lagi terkait manajemen zakat dan } \\
\text { wakaf. }\end{array}$ \\
\hline
\end{tabular}

Berdasarkan sarana dan prasarana Prodi MAZAWA dan masukan-masukan dari stakeholder di atas, maka berikut ini memuat kekuatan (strengths, S), kelemahan (weaknesses, W), peluang (opportunities, O), dan ancaman (threats, T), yang teridentifikasi:

\begin{tabular}{|c|c|}
\hline Strengths (kekuatan) & $\begin{array}{l}\text { Weaknesses } \\
\text { (kelemahan) }\end{array}$ \\
\hline $\begin{array}{l}\text { - Sarana dan prasarana } \\
\text { pembelajaran cukup memadai } \\
\text { - Sarana dan prasarana } \\
\text { dimanfaatkan sesuai dengan } \\
\text { fungsinya } \\
\text { - Media penunjang pembelajaran, }\end{array}$ & $\begin{array}{l}\text { - } \text { Pemeliharaan sarana dan } \\
\text { prasarana tidak optimal } \\
\text { - } \text { Masih terbatasnya sarana } \\
\text { pendukung } \\
\text { - Pengalokasian dana } \\
\text { pemeliharaan masih terbatas }\end{array}$ \\
\hline
\end{tabular}




\begin{tabular}{|c|c|}
\hline $\begin{array}{l}\text { seperti perpustakaan, komputer, } \\
\text { internet, laboratorium bahasa, } \\
\text { komputer, peradilan serta falak } \\
\text { dan ibadah pada prodi } \\
\text { Manajemen Zakat dan Wakaf } \\
\text { tersedia } \\
\text { - Tersedianya Laboratorium } \\
\text { ZISWAF Prodi MAZAWA } \\
\text { - Pengadaan sarana dan } \\
\text { pemeliharaan sesuai dengan } \\
\text { master plan }\end{array}$ & $\begin{array}{l}\text { - Dalam pemanfa-atannya } \\
\text { kadang-kadang melebihi } \\
\text { kemampuan. } \\
\text { - Masih kurangnya referensi } \\
\text { buku-buku tentang Manajemen } \\
\text { Zakat dan Wakaf. }\end{array}$ \\
\hline Opportunities (peluang) & Threats (ancaman). \\
\hline $\begin{array}{l}\text { - Perlu ditingkatkan pemanfaatan } \\
\text { sarana dan prasarana yang sudah } \\
\text { ada di Prodi MAZAWA. } \\
\text { (BAZNAS Karanganyar) } \\
\text { - Perkembangan teknologi } \\
\text { informasi yang sangat cepat } \\
\text { berdampak pada keharusan } \\
\text { melakukan updating sistem } \\
\text { informasi secara berkelanjutan. } \\
\text { Hal ini penting karena untuk } \\
\text { Prodi MAZAWA dibutuhkan } \\
\text { pengembangan SIM dan SIA } \\
\text { dalam pengenalan pengelolaan } \\
\text { ZISWAF untuk mahasiswa. } \\
\text { (BAZNAS Sragen). } \\
\text { - Perlu penguatan } \\
\text { pengembangan Laboratorium } \\
\text { ZISWAF Mazawa. (LAZNAS } \\
\text { AL-AZHAR) }\end{array}$ & $\begin{array}{l}\text { - } \text { Pemeliharaan sarana } \\
\text { pembelajaran bergantung pada } \\
\text { pemerintah } \\
\text { - Cepat rusak karena melebihi } \\
\text { kelebihan beban penggunaan } \\
\text { - Kadang-kadang digunakan } \\
\text { bukan untuk kepentingan } \\
\text { pembelajaran } \\
\text { - Sarana pendukung kurang } \\
\text { pengawasan dan pengamanan } \\
\text { - Tidak terurusnya sarana dan } \\
\text { prasarana dengan baik. }\end{array}$ \\
\hline
\end{tabular}

\subsection{Pembahasan}

\section{a. Strategi Pengembangan Program Studi MAZAWA Berbasis Kebutuhan Masyarakat}

Prodi Manajemen Zakat dan Wakaf akan menetapkan sejumlah strategi Pengembangan Prodi dengan berlandaskan Renstra Fakultas Syariah dan IAIN Surakarta dan sesuai tuntutan dan kebutuhan masyarakat (Stakeholders). Penyusunan strategi pengembangan Prodi Manajemen Zakat dan Wakaf menggunakan analisis SWOT. Penyusunan Strategi Pengembangan Prodi Manajemen Zakat dan Wakaf dapat dilihat pada tabel berikut ini:

Tabel 4.9 Matrik Penentuan Strategi Pengembangan Prodi Manajemen Zakat dan Wakaf 


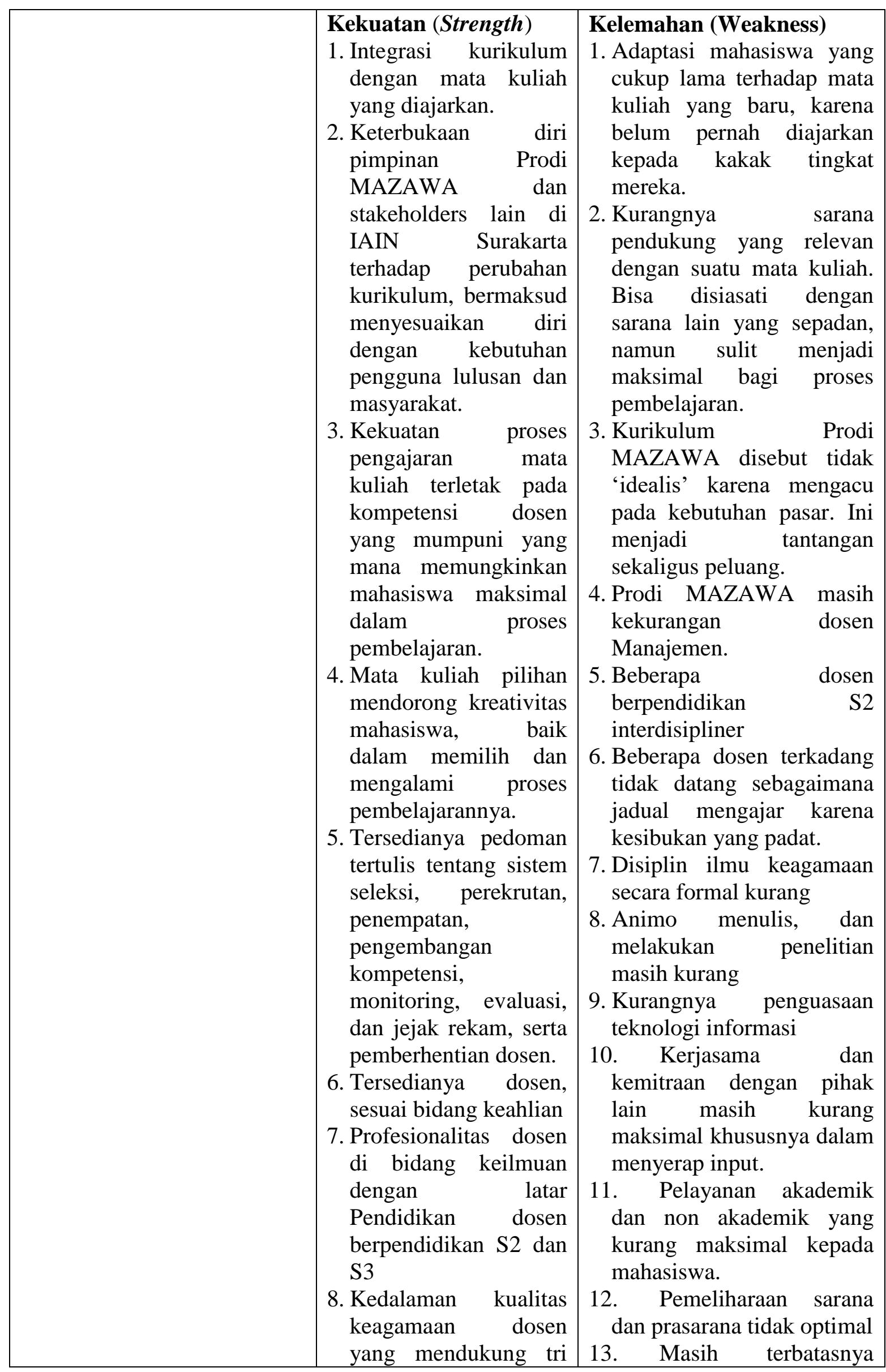




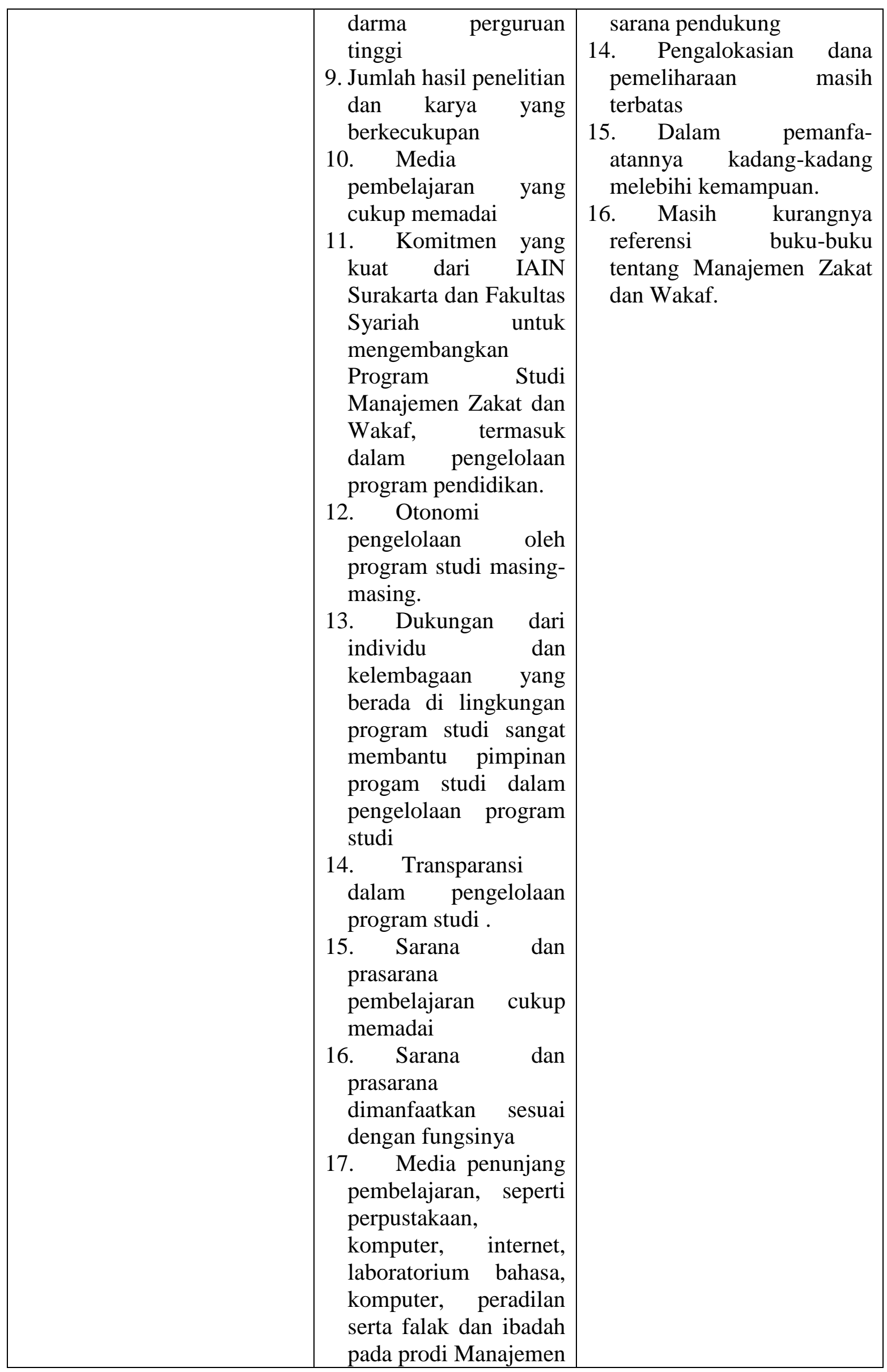




\begin{tabular}{|c|c|c|}
\hline & $\begin{array}{l}\text { Zakat dan Wakaf } \\
\text { tersedia } \\
\text { 18. Tersedianya } \\
\text { Laboratorium } \\
\text { ZISWAF Prodi } \\
\text { MAZAWA } \\
\text { 19. Pengadaan sarana } \\
\text { dan pemeliharaan } \\
\text { sesuai dengan master } \\
\text { plan. }\end{array}$ & \\
\hline Peluang (opportunity) & S-O Strategies & W-O Strategies \\
\hline 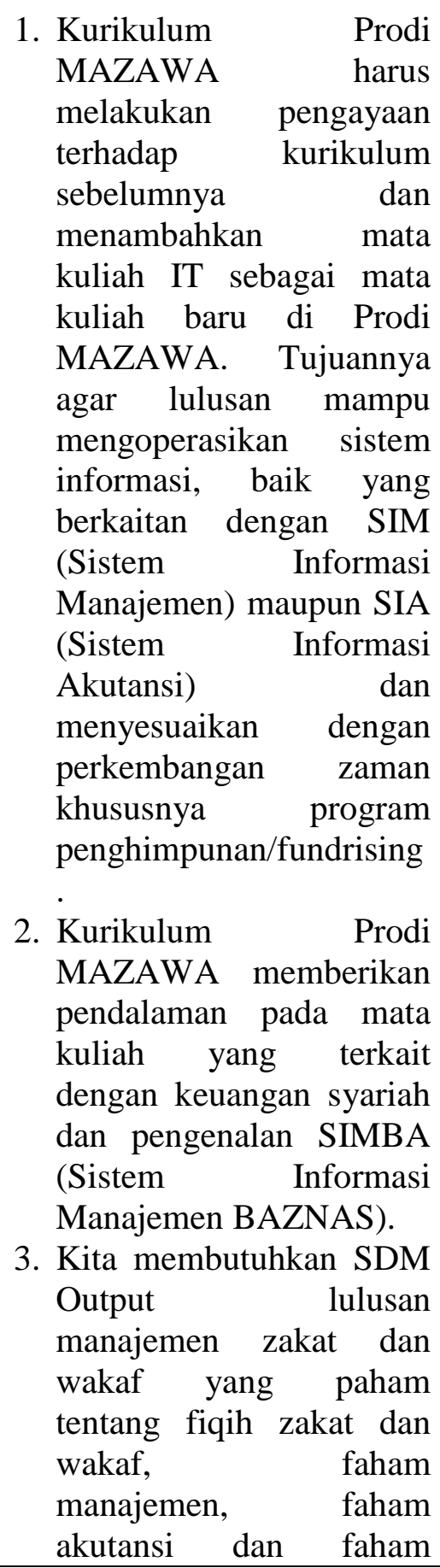 & 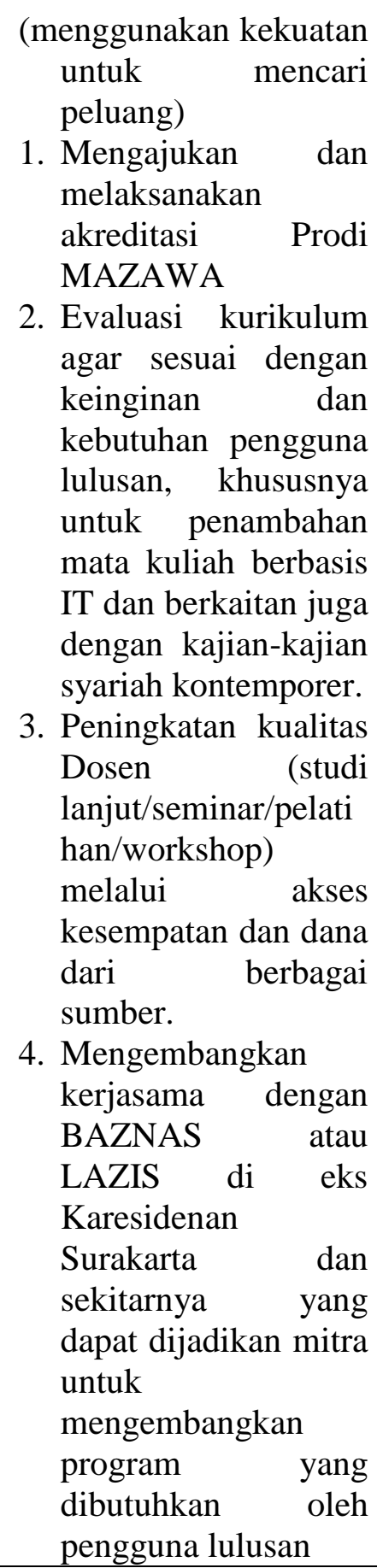 & $\begin{array}{l}\text { (memanfaatkan peluang } \\
\text { untuk mengatasi } \\
\text { kelemahan) } \\
\text { 1. Meningkatkan kerja sama } \\
\text { dengan instansi } \\
\text { pemerintah dan swasta } \\
\text { untuk menyalurkan } \\
\text { lulusan yang kompeten. } \\
\text { 2. Meningkatkan kerjasama } \\
\text { antara Program Studi } \\
\text { MAZAWA dengan pihak } \\
\text { luar atau institusi lain } \\
\text { dalam hal penelitian } \\
\text { ataupun publikasi. } \\
\text { 3. Pengelompokan minat } \\
\text { bidang studi } \\
\text { dosen/mahasiswa. } \\
\text { 4. Menambah koleksi buku- } \\
\text { buku referensi tentang } \\
\text { manajeman zakat dan } \\
\text { wakaf di Perpustakaan } \\
\text { Fakultas dan Institut. }\end{array}$ \\
\hline
\end{tabular}




\begin{tabular}{|c|c|c|}
\hline 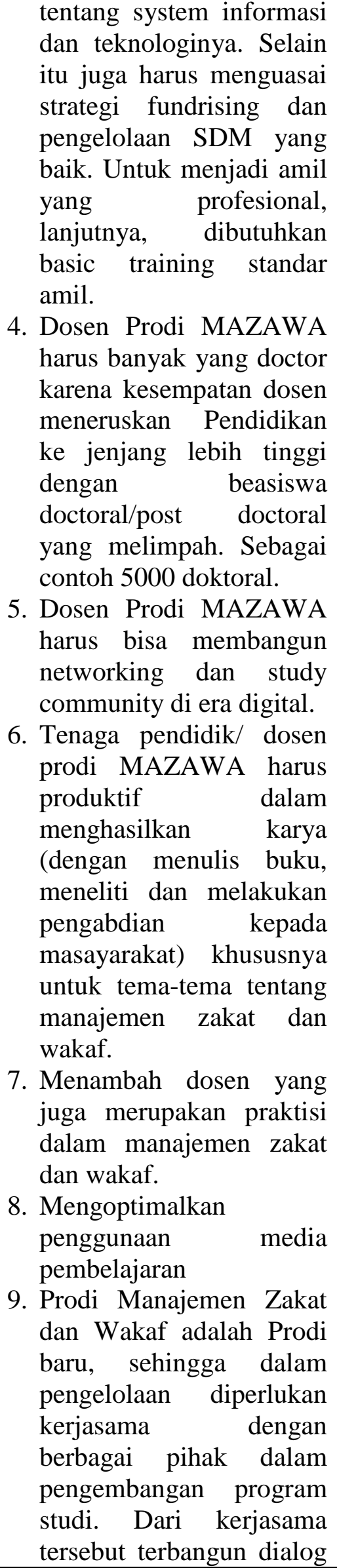 & 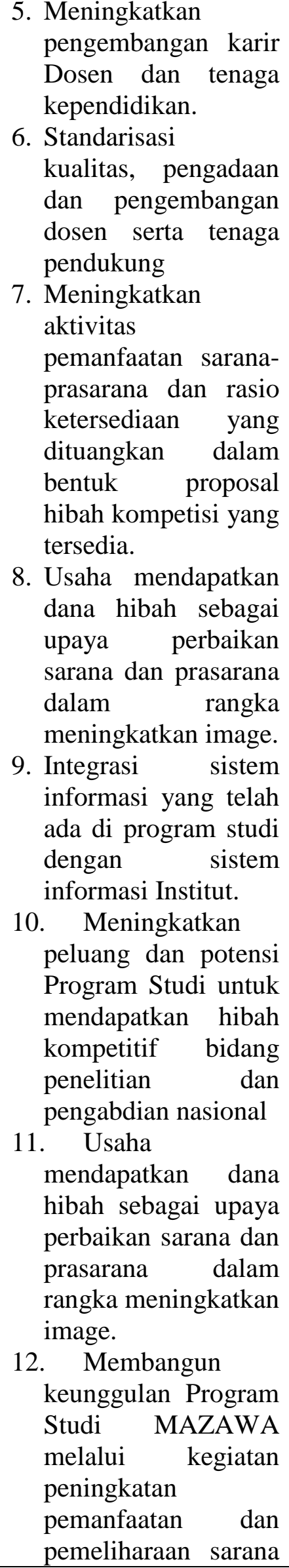 & \\
\hline
\end{tabular}


yang intensif dengan para praktisi lembaga zakat wakaf. Melalui dialog demikian, diharapkan kesenjangan antara teori dan kebutuhan praktis pengelolaan zakat wakaf dapat dihindari.

10. Perlu mengembangkan

kerjasama dengan BAZNAS atau LAZIS di eks Karesidenan Surakarta dan sekitarnya yang dapat dijadikan mitra untuk mengembangkan program yang dibutuhkan oleh pengguna lulusan.

11. Perlu memperkuat legalitas laboratorium ZISWAF Fasya sehingga bisa digunakan oleh mahasiswa untuk praktik langsung dalam pengelolaan ZISWAF. Kami juga akan menjalin kerjasama dengan laboratorium ziswaf Fasya sebagai Mitra Pengumpul Zakat (MPZ) Laznas Al-Azhar.

12. Perlu adanya study banding terhadap pengelolaan prodi MAZAWA di beberapa Perguruan Tinggi yang lain.

13. Perlu ditingkatkan pemanfaatan sarana dan prasarana yang sudah ada di Prodi MAZAWA.

14. Perkembangan teknologi informasi yang sangat cepat berdampak pada keharusan melakukan updating sistem informasi secara berkelanjutan. Hal ini penting karena untuk yang ada.

13. Penyusunan skala prioritas pendanaan sarana-prasarana MK yang belum memadai 


\begin{tabular}{|c|c|c|}
\hline $\begin{array}{l}\text { Prodi MAZAWA } \\
\text { dibutuhkan } \\
\text { pengembangan SIM dan } \\
\text { SIA dalam pengenalan } \\
\text { pengelolaan ZISWAF } \\
\text { untuk mahasiswa. } \\
\text { 15. Perlu penguatan dan } \\
\text { pengembangan } \\
\text { Laboratorium ZISWAF } \\
\text { Mazawa. }\end{array}$ & & \\
\hline 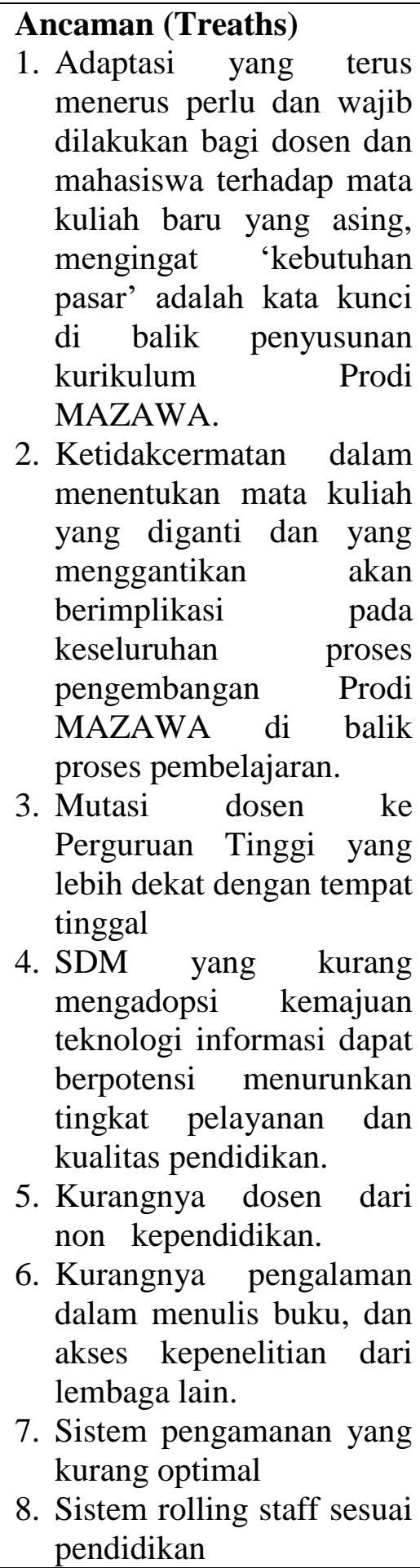 & $\begin{array}{l}\text { S-T strategies } \\
\text { (menggunakan kekuatan } \\
\text { untuk mengatasi } \\
\text { ancaman) } \\
\text { 1. Workshop kurikulum } \\
\text { sebagai upaya } \\
\text { mensinergikan } \\
\text { materi tiap mata } \\
\text { kuliah. } \\
\text { 2. Memperkuat } \\
\text { legalitas } \\
\text { laboratorium } \\
\text { ZISWAF } \\
\text { dengan masya } \\
\text { kemitraan dengan } \\
\text { BAZNAS atau } \\
\text { LAZIZ. } \\
\text { 3. Peningkatan kualitas } \\
\text { Dosen (studi } \\
\text { lanjut/seminar/pelati } \\
\text { han/workshop) } \\
\text { melalui akses } \\
\text { kesempatan dan dana } \\
\text { dari berbagai } \\
\text { sumber. } \\
\text { 4. Standarisasi } \\
\text { kualitas, pengadaan } \\
\text { dan pengembangan } \\
\text { dosen serta tenaga } \\
\text { pendukung. } \\
\text { 5. Meningkatkan } \\
\text { proses pendidikan } \\
\text { secara profesional } \\
\text { sehingga } \\
\text { menghasilkan } \\
\text { lulusan } \\
\text { kompetitif. } \\
\text { penerapan } \\
\text { perbaikan }\end{array}$ & $\begin{array}{l}\text { W-T strategies } \\
\text { (meminimalkan kelemahan } \\
\text { dan mengatasi ancaman) } \\
\text { 1. Mengembangkan } \\
\text { kerjasama dibidang } \\
\text { pendidikan, penelitian } \\
\text { dan pengabdian kepada } \\
\text { masyarakat dengan pihak } \\
\text { eksternal baik ditingkat } \\
\text { lokal, nasional maupun } \\
\text { internasional keberadaan } \\
\text { 2. Promosi Studi } \\
\text { Program melalui } \\
\text { MAZAWA baik } \\
\text { prestasi mahasiswa baik } \\
\text { dalam kegiatan akademik } \\
\text { maupun non akademik. } \\
\text { 3. Melakukan kerjasama } \\
\text { dengan kelompok- } \\
\text { kelompok studi dalam } \\
\text { kerjasama yang dibangun } \\
\text { Prodi MAZAWAdengan } \\
\text { stakeholder dalam bentuk } \\
\text { penelitian dan publikasi. }\end{array}$ \\
\hline
\end{tabular}




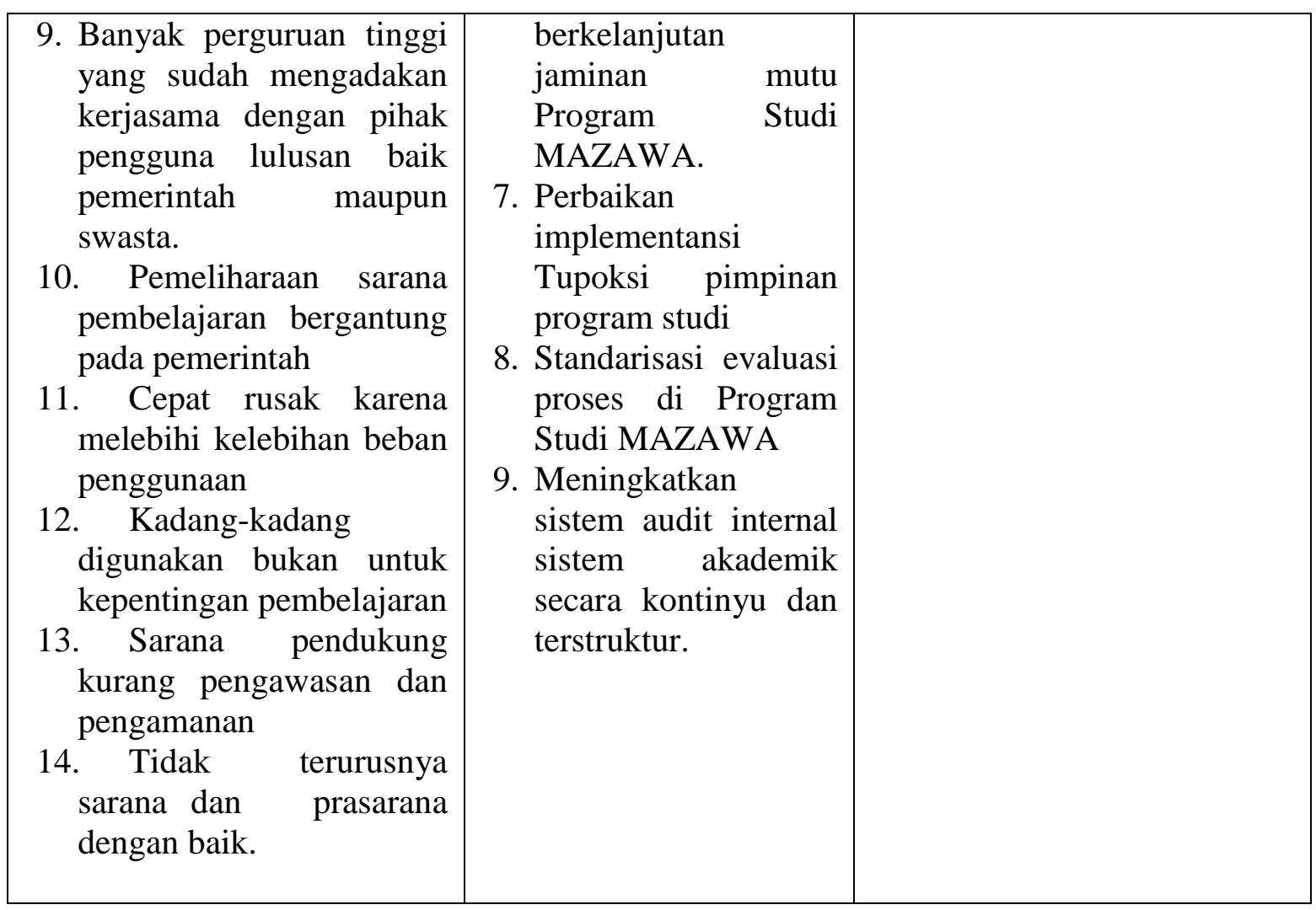




\section{Simpulan}

Prodi Manajemen Zakat dan Wakaf merencenakan strategi pengembangan prodi berbasis masyarakat sebagai salah satu upaya eksistensi prodi dengan kebutuhan pengguna lulusan (stakeholders). Diantara strategi pengembangan prodi MAZAWA yang akan dilaksanakan diantarnya menyusun rencana strategis jangka pendek, menengah dan jangka panjang. Rencana strategis jangka pendek prodi MAZAWA diantaranya mengajukan dan melaksanakan akreditasi Prodi MAZAWA untuk tahun 2019, melaksanakan evaluasi kurikulum, workshop kurikulum, mengembangkan kerjasama dengan BAZNAS atau LAZIS di eks Karesidenan Surakarta, promosi keberadaan Program Studi MAZAWA melalui prestasi mahasiswa baik dalam kegiatan akademik maupun non akademik. 


\section{DAFTAR PUSTAKA}

A.S. Hornbay, Oxford Advanced Leaners Dictionary of Current English (Oxford: Oxford University Press, 1963.

Amin, Tunggal Wijaya, Kamus Bisnis dan Manajemen. Jakarta: Rineka Cipta, 2005.

Anton Bekker dan Ahmad Charis Zubair, Metodologi Penelitian Filsafat. Yogyakarta: Kanisius, 1999.

Direktorat Jenderal Manajemen Pendidikan Dan Menengah, Panduan Penyelenggaraan Progam Rintisan SMA Bertaraf Internasional. Jakarta: Depdiknas, 2008.

Engkoswara, Menuju Indonesia Modern 2020. Bandung: Yayasan Amal Keluarga, 1999.

Hadari Nawawi, Metode Penelitian Bidang Sosial. Bandung: Tarsito, 1985.

Hikmat, Manajemen Pendidikan. Bandung: Pustaka Setia, 2009.

Husaini Usman, Manajemen Teori, Praktik dan Riset Pendidikan. Jakarta: Bumi Aksara, 2008.

Kartodirjo, Penelitian Sosial. Jakarta : Ghalia Press, 1986. 2004

Lexy J. Moleong, Metode Penelitian Kualitatif. Bandung: Remaja Rosdakarya,

Miles, MB, \& Huberman MA, Qualitative Data Analisys a Sourse Book of New Method, London: Sage Publication Ltd.

Muhaimin, Arah Baru Pengembangan Pendidikan Islam. Bandung: Nuansa, 2003.

Nasution, Metode Research. Jakarta: Bumi Aksara, 2003.

Oemar Hamalik, Manajemen Pengembangan Kurikulum. Bandung: Remaja Rosdakarya.

Sondang P Siagian, Filsafat Administrasi, Jakarta: Gunung Agung, 1997.

Suharsimi Arikunto, Prosedur Penelitian Suatu Pendekatan Praktek. Yogyakarta : Rineka Cipta, 1997.

Sukandarrumidi, Metodologi Penelitian. Yogyakarta: Gadjah Mada University Press, 2002.

Suryobroto, Manajemen Pendidikan di Sekolah. Jakarta: Rineka Cipta, 2004.

Sutrisno Hadi, Metodologi Research. Yogyakarta : UGM Press, 1993.

Thomas E Curtis. Bidwell Wilma W, Curriculum and Instruction for Emerging Adolescent. New York: Albany, 1976.

Tilaar, Paradigma Baru Pendidikan Nasional. Jakarta: Reneka Cipta, 2000.

Undang-Undang Nomor 20 Tahun 2003 tentang Sistem Pendidikan Nasional, Pasal 50 Ayat. 3.

Winarno Surakhmad, Dasar dan Tehnik Research. Bandung: Tarsito, 1978.

Winarno Surakhmad, Pengantar Penelitian Ilmiah: Dasar dan Metode Teknik. Bandung: Tarsio, 1990. 